\title{
A composite six bp in-frame deletion in the melanocortin 1 receptor $(M C 1 R)$ gene is associated with the Japanese brindling coat colour in rabbits (Oryctolagus cuniculus)
}

\author{
Luca Fontanesi ${ }^{1 *}$, Emilio Scotti ${ }^{1}$, Michela Colombo ${ }^{1}$, Francesca Beretti ${ }^{1}$, Lionel Forestier ${ }^{2}$, Stefania Dall'Olio ${ }^{1}$,
} Séverine Deretz ${ }^{3}$, Vincenzo Russo ${ }^{1}$, Daniel Allain ${ }^{4}$, Ahmad Oulmouden²

\begin{abstract}
Background: In the domestic rabbit (Oryctolagus cuniculus), classical genetic studies have identified five alleles at the Extension locus: $E^{D}$ (dominant black), $E^{S}$ (steel, weaker version of $E^{D}$ ), $E$ (wild type, normal extension of black), $e^{J}$ (Japanese brindling, mosaic distribution of black and yellow) and $e$ (non-extension of black, yellow/red with white belly). Sequencing almost the complete coding sequence (CDS) of the rabbit MC1R gene, we recently identified two in-frame deletions associated with dominant black (c.280_285del6; alleles $E^{D}$ or $E^{S}$ ) and recessive red (c.304_333del30; allele e) coat colours. It remained to characterize the $e^{J}$ allele whose phenotypic effect is similar to the Orange and Sex-linked yellow loci of cat and Syrian hamster.
\end{abstract}

Results: We sequenced the whole CDS in 25 rabbits of different coat colours including 10 Japanese and 10 Rhinelander (tricolour) rabbits and identified another 6 bp-in frame deletion flanked by a G > A transition in $5^{\prime}$ (c. [124G>A;125_130del6]) that was present in all animals with Japanese brindling coat colour and pattern. These mutations eliminate two amino acids in the first transmembrane domain and, in addition, cause an amino acid substitution at position 44 of the wild type sequence. Genotyping 371 rabbits of 31 breeds with different coat colour this allele ( $\left.e^{\prime}\right)$ was present in homozygous state in Japanese, Rhinelander and Dutch tricolour rabbits only (except one albino rabbit). Rabbits with $e^{J} / e^{J}$ genotype were non fixed at the non-agouti mutation we previously identified in the ASIP gene. Segregation in $F_{1}$ and $F_{2}$ families confirmed the order of dominance already determined by classical genetic experiments with a possible dose effect evident comparing $e^{J} / e^{J}$ and $e^{J} / e$ animals. $M C 1 R$ mRNA was expressed in black hair skin regions only.

Conclusions: The c.[124A;125_130del6] allele may be responsible for a MC1R variant determining eumelanin production in the black areas. However, the mechanism determining the presence of both red and black hairs in the same animal seems more complex. Expression analyses of the c.[124A;125_130del6] allele suggest that MC1R transcription may be regulated epigenetically in rabbits with the Japanese brindling phenotype. Further studies are needed to clarify this issue.

\section{Background}

Coat colour in mammals is determined by the presence, distribution and biochemical activity of the melanocytes, which are specialized cells where eumelanins (black/ brown pigments) and pheomelanins (yellow/red pigments)

\footnotetext{
*Correspondence: luca.fontanesi@unibo.it
'DIPROVAL, Sezione di Allevamenti Zootecnici, University of Bologna, Via F.lli

* Correspondence: luca.fontanesi@unibo.it
'DIPROVAL, Sezione di Allevamenti Zootecnici, University of Bologna, Via F.lli Rosselli 107, 42123 Reggio Emilia, Italy
}

(c) 2010 Fontanesi et al; licensee BioMed Central Ltd. This is an Open Access article distributed under the terms of the Creative Commons Attribution License (http://creativecommons.org/licenses/by/2.0), which permits unrestricted use, distribution, and reproduction in any medium, provided the original work is properly cited. affect cost colour in mice regulating or altering meloncyte development and migration during embryogenesis, melanocyte morphology and functions, its components and its enzymatic machinery [1,2]. However, Extension and Agouti are the main loci that affect the production and relative amount of these two melanin types in the melanocytes [3]. These loci show epistatic interactions and usually wild type Extension is required for Agouti 
expression. Dominant alleles at the Extension locus produce black pigmentation, whereas recessive alleles extend the production of pheomelanins, causing yellow/red/pale pigmentation. On the contrary, dominant Agouti alleles determine pheomelanic phenotypes whereas recessive alleles cause black coat colour with a few exceptions.

The Extension locus encodes the melanocortin 1 receptor (MC1R) [4]. This protein belongs to the seven transmembrane $\mathrm{G}$ protein coupled receptors that binds the $\alpha$ melanocyte-stimulating hormone $(\alpha \mathrm{MSH})$ inducing eumelanin synthesis. The Agouti locus encodes the agouti signaling protein (ASIP) that is a small paracrine signalling protein (131-135 amino acids in different mammals) [5]. ASIP affects pigmentation blocking the $\alpha \mathrm{MSH}-\mathrm{MC} 1 \mathrm{R}$ interaction which, in turn, causes a switch in pigment type from eumelanins to phaeomelanins $[6,7]$.

Mutations of the $M C 1 R$ gene associated with different coat colours have been described in several species (mice [4], humans [8], guinea pigs [9], cattle [10-12], pigs [13,14], horses [15], sheep [16], goats [17], dogs $[18,19]$, foxes [20,21], bears [22], felids [23], pocket and beach mice [24,25], squirrels [26], chickens [27], Japanese quails [28], bananaquits [29], guinea fowl [30] and reptiles [31]) in which gain of function mutations produce black/dark coat colour, whereas loss of function mutations usually cause yellow/red coat colour.

In the domestic rabbit (Oryctolagus cuniculus), classical genetic studies involving crossbreeding experiments among breeds with different coat colours have identified five alleles at the Extension locus: $E^{D}$ (dominant black), $E^{S}$ (steel, weaker version of $E^{D}$ ), $E$ (wild type, normal grey or normal extension of black), $e^{J}$ (Japanese brindling, mosaic distribution of black and yellow) and $e$ (non-extension of black, yellow/red with white belly) [3,32-34]. The order of dominance is the following: $E^{D}>E^{S}>E>e^{J}>e$, with possible partial dominance of $E^{D}$ over $E^{S}$ and of $E^{S}$ over $E[3,32-34]$. Sequencing almost the complete coding sequence (CDS) of the rabbit $M C 1 R$ gene, we recently identified two in-frame deletions associated with dominant black (c.280 285del6; alleles $E^{D}$ and/or $E^{S}$ ) and recessive red (c.304_333del30; allele $e$ ) coat colours, respectively [35]. The dominant black deletion eliminates two amino acids in the second transmembrane domain (Figure 1). We could not clarify if this deletion corresponds to the $E^{D}$ or $E^{S}$ allele as sequencing and genotyping in a large number of rabbits across 30 breeds/ strains did not identify any other mutation associated with dominant black (and/or steel). Therefore it could be hypothesized the existence of only one dominant black allele and the presence of modifier genes might be the reason of different intensities of black (steel) of the two putative alleles identified by classical genetic studies. The recessive red deletion eliminates 10 amino acids of the first extracellular loop (Figure 1) and was in homozygous state in all yellow/red rabbit breeds and strains (Burgundy Fawn, Gold Saxony, New Zealand Red, and Thuringian breeds and yellow/red animals of other breeds not fixed for any coat colour) [35]. It remained to characterize the $e^{J}$ (Japanese brindling) allele. The Japanese brindling coat colour variety probably appeared in France within the second half of the 19th century and subsequently was introduced in England and other countries [36,37]. The Japanese brindling pattern can be defined as a yellow coat mottled with black, therefore this coat colour seems determined by the presence of two different types of melanocytes in different skin areas, one producing eumelanin and another one producing pheomelanin $[3,33,36,37]$. The $e^{J}$ allele should be fixed in the Japanese and Rhinelander breeds $[33,34]$. The former breed (named after its coat colour) has the classic mottled phenotype (Figure 2A) that is similar to the tortoiseshell pattern observed in female cats and female Syrian hamsters. The coat colour in these two species is caused by the Orange and Sex-linked yellow loci, respectively, that are two non-homologous X chromosome loci $[38,39]$. The coat colour phenotype determined by the rabbit $e^{J}$ allele is also similar to that determined in guinea-pig by the $e^{p}$ (tortoiseshell) allele at the Extension locus described by classical genetic studies $[40,41]$ but not characterized at the molecular level, yet [9]. The Rhinelander rabbit breed has a tricolour pattern with black, yellow and white areas (Figure 2B). The white regions are caused by the absence of mature melanocytes due to a dominant English spotting locus allele [3,32,33,35,42]. The coloured patches are much larger than those of the tortoiseshell-like pattern probably because a reduced number of melanoblasts in the skin allows for a spatial expansion of the melanoblast-derived clones. This tricolour pattern is similar to the calico coat colour in cat determined by the epistatic interaction between the Spotting and Orange loci [38] and in guinea-pigs to the effect of the white-spotting factor $s$ in $e^{p} / e^{p}$ animals [3]. An Extension allele with similar (but not overlapping) phenotypic effect to the rabbit $e^{J}$ allele has been described in pig [14]. In this species the $E^{p}$ allele, that is caused by a frameshift mutation (a 2 bp insertion) in the $M C 1 R$ coding sequence, determines red coat colour in Hereford, Linderöd and Tamworth pigs but frequent somatic reversions re-establish the correct reading frame and produce black coat colour in skin areas determining a spotted phenotype in a red background. As a matter of fact, epistatic effects of the Dominant white/KIT locus on this Extension allele might determine the white and black spotted phenotype or the complete white colour of some pig breeds $[14,43]$. 

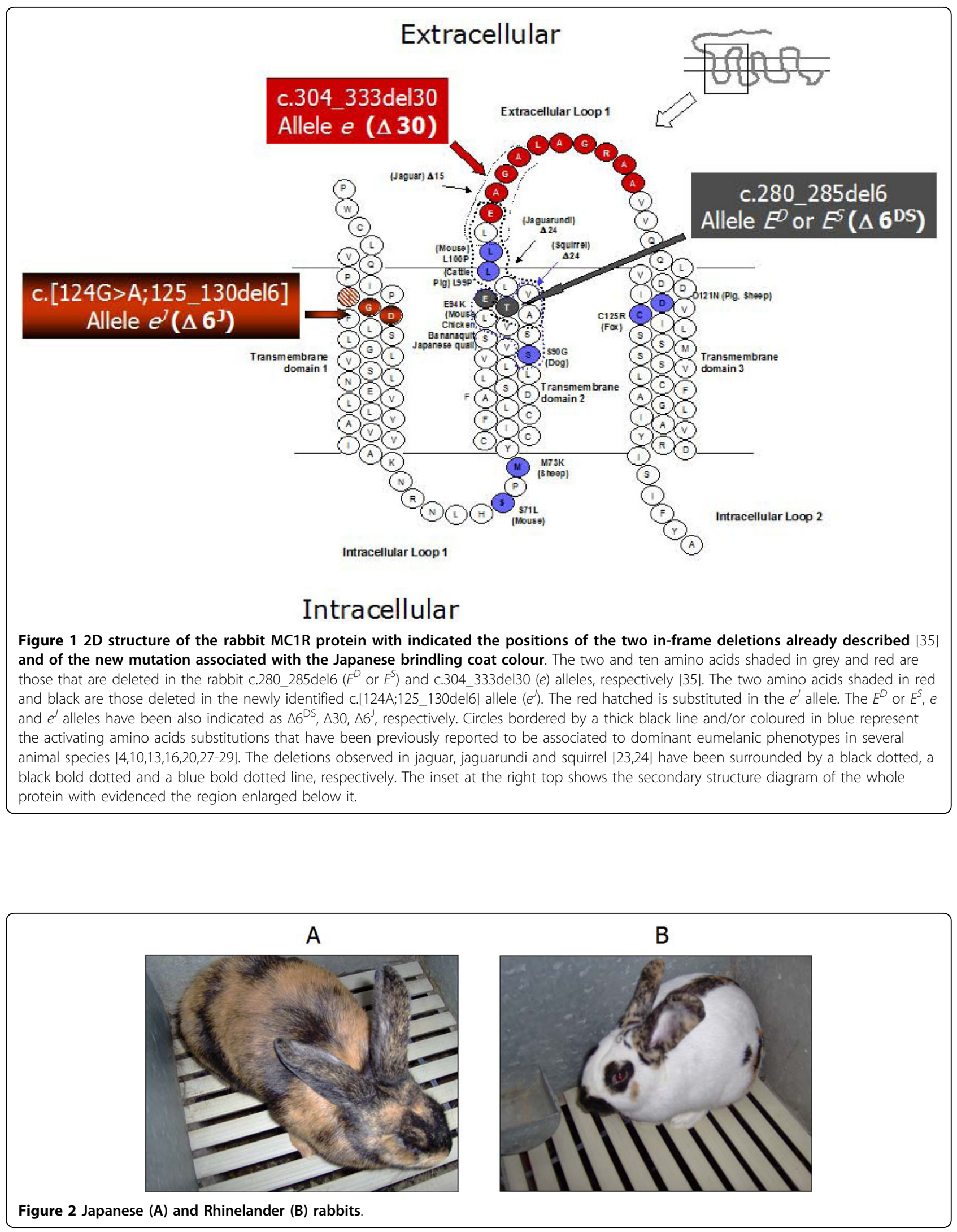
Here we investigated the $M C 1 R$ gene in Japanese and Rhinelander rabbits and identified a novel in-frame deletion associated with the $e^{J}$ coat colour. In addition we analysed in these rabbits the $M C 1 R$ gene expression in skin specimens of different coloured regions.

\section{Results}

\section{Rabbit MC1R gene sequences}

In our previous study we did not completely sequence the CDS of the rabbit MC1R gene and for some breeds the Extension allele status was obtained by genotyping the two in-frame deletions identified and not by sequencing [35]. Here we amplified and sequenced $1348 \mathrm{bp}$ (considering a wild type sequence) of the $M C 1 R$ gene (the whole CDS of $954 \mathrm{bp}, 14 \mathrm{bp}$ of the 5'-untranslated region and $380 \mathrm{bp}$ of the 3'-untranslated region) in 25 rabbits of different breeds including 10 animals of the Japanese and 10 animals of the Rhinelander breeds. The sequences obtained from Burgundy Fawn and Thuringian rabbits confirmed the presence of the $30 \mathrm{bp}$ inframe deletion (c.304_333del30) as the determinant of the $e$ allele (EMBL accession number FN658678). The c.280_285del6 was identified in a Checkered Giant rabbit carrying the $E^{D}$ (or $E^{S}$ ) allele confirming what we previously reported [35] (EMBL accession number FN658677). Surprisingly, another 6 bp deletion flanked by a G>A transition in 5' (c.[124G>A;125_130del6]), was identified in all Japanese and Rhinelander sequenced rabbits (EMBL accession number FN658679). The 6 bp deletion included 2 nucleotides of codon 42, three nucleotide of codon 43 and one nucleotide of codon 44 . Together with the $\mathrm{G}>\mathrm{A}$ transition this 6 bp deletion eliminates two amino acids in the first transmembrane domain (D and $G$ at positions 42 and 43 of the wild type sequences) and, in addition, causes an amino acid substitution at position 44 (p.L44T), considering the wild type sequences (Figure 1). EMBL accession numbers of the wild type sequences (obtained from Giant Grey and Blue Vienna rabbits; see [35]) are FN658675 and FN658676.

\section{Genotyping in different rabbit breeds}

In order to confirm the putative role of this new allele in determining the Japanese and tricolour phenotypes we genotyped by fragment analysis the c.125_130del6 mutation in a total of 371 rabbits belonging to 31 breeds. Genotyping data are reported in Table 1 (see Figures $3 \mathrm{E}$ and $3 \mathrm{~F}$ as examples of the genotyping results). These animals were also genotyped for the other two in-frame deletions associated with the $e$ and $E^{D}$ (or $E^{S}$ ) alleles [35]. All rabbits of the Japanese, Rhinelander and Dutch tricolour breeds were homozygous for the new composite mutation. This mutation was also identified: 1) in heterozygous condition with the c.280_285del6 allele, in two black and white Checkered Giant rabbits belonging to a colony in which there was segregation of the tricolour and black and white phenotypes; 2) in heterozygous condition with a wild type Extension allele in one Giant Grey rabbit (with wild type coat colour); 3) homozygous in one Angora albino rabbit. The presence of this mutation in other animals that do not have the Japanese or tricolour phenotype demonstrates the dominance of the c.280_285del6 and of the wild type Extension alleles over the c. [124A;125_130del6] allele, confirming the results of classical genetic studies $[1,33,36,37]$. In addition, albino rabbits do not express any other coat colour locus allele due to its status caused by a mutation in the tyrosinase (TYR) gene [44]. All rabbits were also genotyped for the insertion in the ASIP gene (c.5_6insA) we recently identified to be the causative mutation of the nonagouti black coat colour [45]. Interestingly, all three possible genotypes were identified in the Japanese and Rhinelander rabbits whereas 7 Dutch tricolour rabbits were homozygous for the c.5_6insA mutation and one was heterozygous. To exclude the presence of additional ASIP mutations we sequenced the three coding exons and parts of the intronic regions in two Japanese or Rhinelander animals for each c.5_6insA genotype. No other polymorphisms were identified apart those already reported [45].

\section{Family based analyses and colour segregation}

Three $F_{1}$ families were created crossing animals of different breeds (Additional file 1). All parental animals were homozygous for the c.5_6insA ASIP mutation. The first family was obtained by crossing a Rhinelander buck with a Thuringian doe homozygous for the c.304_333del30 mutation ( $e$ allele). Of the 7 obtained $\mathrm{F}_{1}$ rabbits, 2 had the Japanese coat colour pattern (but with predominance of the yellow/red colour) and 5 were similar to the buck (tricolour) even if, again, they showed a predominance of the yellow/red spots over the black spots. This confirms the dominance of the $c$. [124A;125_130del6] allele over the $e$ allele and that there was a dose effect of the new mutation that was in heterozygous condition in the $F_{1}$ animals. A second $F_{1}$ family was created by crossing the same Rhinelander buck with a Japanese doe obtaining $9 \mathrm{~F}_{1}$ rabbits. Four of them had the same coat colour pattern of the buck and 5 were like the doe. In this family, the tricolour or Japanese brindling phenotypes were determined by the segregation of a dominant English spotting allele (heterozygous in the Rhinelander father), like in the previous family $[3,32,33,35,42]$. The third $F_{1}$ family was constituted by $10 \mathrm{~F}_{1}$ rabbits obtained by crossing a Checkered Giant buck (homozygous for the c.280_285del6 allele) and the Japanese doe of the 
Table 1 Genotypes of the novel MC1R 6 bp composite deletion (c.[124G>A;125_130del6] or $\Delta 6^{J}$ ) in rabbits of different breeds

\begin{tabular}{|c|c|c|c|c|}
\hline Breed (no. of animals) & Coat colour (no. of animals) ${ }^{1}$ & Genotyp & & \\
\hline & & $181 / 181$ & $181 / 187$ & $187 / 187$ \\
\hline Alaska (7) & self black & - & - & 7 \\
\hline Angora (1) & albino-white & 1 & - & - \\
\hline Belgian Hare (3) & reddish laced with black & - & - & 3 \\
\hline Blanc de Hotot (3) & white with black markings & - & - & 3 \\
\hline Blue Vienna (39) & dark blue & - & - & 39 \\
\hline Burgundy Fawn (15) & fawn & - & - & 15 \\
\hline Bristle White (3) & bristle white & - & - & 3 \\
\hline Californian (43) & white with black markings & - & - & 43 \\
\hline Champagne d'Argent (39) & silver as surface colour and dark blue as under-colour & - & - & 39 \\
\hline Checkered Giant (29) & white with black markings & - & 2 & 27 \\
\hline Checkered Small (7) & white with black (6) or blue (1) markings & - & - & 7 \\
\hline Coloured Dwarf (5) & bristle white (2), hare-grey (1), Havana (1), chinchilla (1) & - & - & 5 \\
\hline Dutch (17) & with black markings $\left(9^{*}\right)$, tricolour $\left(8^{* *}\right)^{4}$ & $8^{* *}$ & - & $9^{*}$ \\
\hline Ermine (1) & white with blue eyes & - & - & 1 \\
\hline Fairy Marburg (1) & grey-light blue & - & - & 1 \\
\hline Fairy Pearly (3) & pearling grey & - & - & 3 \\
\hline Giant Chinchilla (21) & chinchilla & - & - & 21 \\
\hline Giant Grey (12) & wild-grey & - & 1 & 11 \\
\hline Giant White (7) & white albino & - & - & 7 \\
\hline Havana (2) & dark brown & - & - & 2 \\
\hline Japanase (32) & Japanese brindling & 32 & - & - \\
\hline Lop (8) & wild-grey (7); with Madagascar markings (1) & - & - & 8 \\
\hline Lop Dwarf (3) & wild-grey (2); self black (1) & - & - & 3 \\
\hline Mini Silver (4) & black with silvering & - & - & 4 \\
\hline New Zealand White (33) & white-albino & - & - & 33 \\
\hline $\operatorname{Rex}(1)$ & black dalmatian & - & - & 1 \\
\hline Rhinelander (11) & white with black and yellow markings (tricolour) & 11 & - & - \\
\hline Silver (10) & black with silvering & - & - & 10 \\
\hline $\operatorname{Tan}(2)$ & black fire & - & - & 2 \\
\hline Thuringian (3) & shaded yellow/brown & - & - & 3 \\
\hline White Vienna (6) & white-blue eyes & - & - & 6 \\
\hline Total (371) & & 52 & 3 & 316 \\
\hline
\end{tabular}

${ }^{1}$ When rabbits with different coat colours were sampled in a breed, the corresponding number of analysed animals is reported.

2 The genotypes are indicated according to the obtained amplified fragments in bp: 181 = fragment with the 6 bp composite deletion (c.[124A;125_130del6] allele indicated also as $\Delta 6^{J}$ ); $187=$ normal fragment, that could be derived from the $E$, $e$ and $E^{D}$ or $E^{S}$ alleles. The number of animals with the three genotypes is reported.

${ }^{3}$ These animals have been genotyped for the c.280_285del6 and c.304_333del30 deletions of the MC1R gene [35] and for the c.5_6insA deletion in the ASIP gene causing the black nonagouti coat colour [45].

${ }^{4}$ For the Dutch breed, asterisks (* ${ }^{* *}$ ) have been included to link their coat colour description to the genotyping results.

previous family. All $\mathrm{F}_{1}$ animals were completely black (no. = 3) or black and white (no. = 7). Again, the black and white $\mathrm{F}_{1}$ rabbits were determined by a dominant English spotting locus allele, heterozygous in the Checkered Giant buck [3,32,33,35,42]. This family confirms the dominance of the c.280_285del6 allele over the c. [124A;125_130del6] allele. $F_{2}$ animals were obtained by crossing two $F_{1}$ rabbits of this family. The $F_{1}$ animals were carriers of the c.[124A;125_130del6] MC1R allele and of the English spotting locus allele. Of the nine $\mathrm{F}_{2}$ rabbits, 4 were completely black (two were homozygous for the c.280_285del6 allele and two had the heterozygous genotype c.280_285del6/c.[124A;125_130del6]), 3 were black and white (one was homozygous for the c.280_285del6 allele and two had the heterozygous genotype c.280_285del6/c.[124A;125_130del6]), 2 had a tricolour phenotype, confirming the segregation of the Japanese brindling coat colour together with homozygosity for the c.[124A;125_130del6] allele in these latter rabbits (data not shown). 


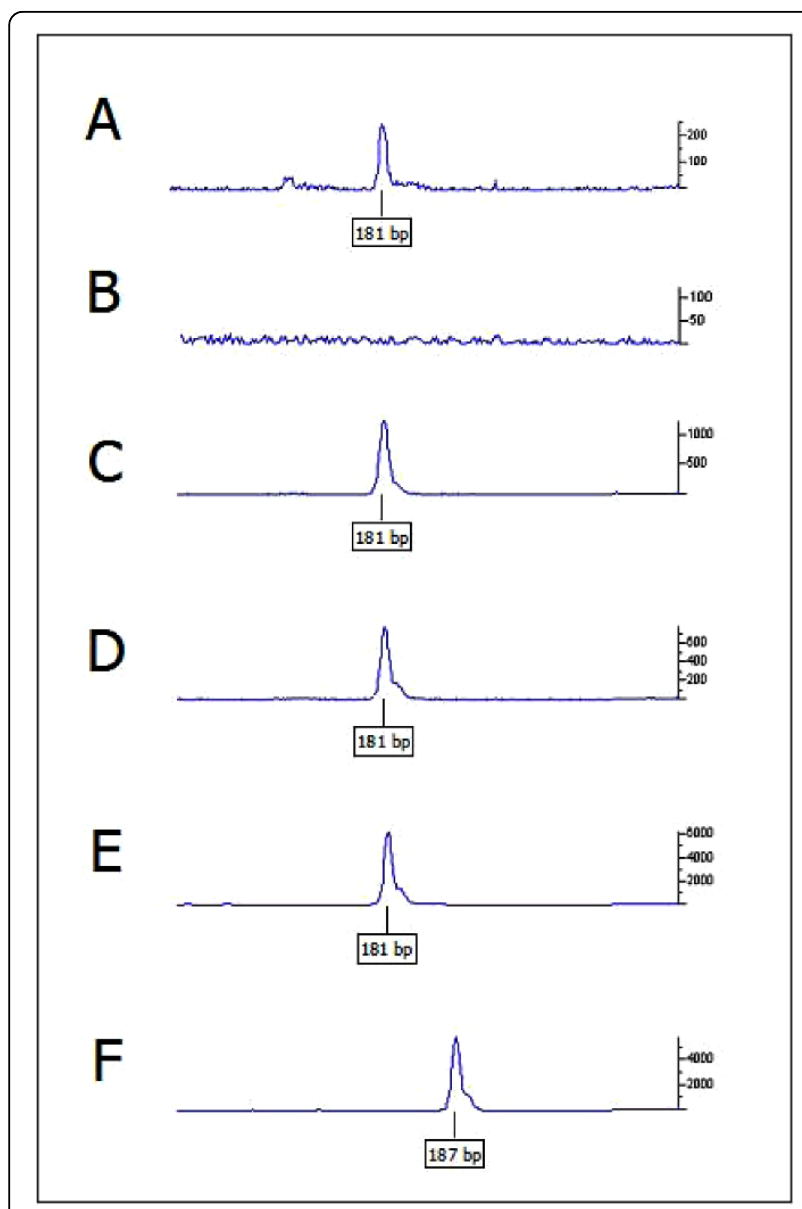

Figure 3 Electropherograms showing the amplified $M C 1 R$ fragments obtained from different sources. MCIR product amplified from A) cDNA obtained from a black hair skin region of a Rhinelander rabbit, B) cDNA obtained from a red hair skin region of a Rhinelander rabbit (the same result was obtained in white hair skin regions), C) genomic DNA isolated from a black hair skin region of a Rhinelander rabbit, D) genomic DNA isolated from a red hair skin region of a Rhinelander rabbit, E) genomic DNA isolated from blood of a Rhinelander rabbit, F) genomic DNA isolated from blood of a Checkered Giant rabbit. No amplification was obtained in B. The Rhinelander rabbit was homozygous for allele $\mathrm{c}$.

[124A;125_130del6] (e') and the Checkered Giant rabbit was homozygous for allele c.280_285del6 ( $E^{D}$ or $\left.E^{S}\right)$. The size of the amplified fragments is reported in the boxes below the electrophoretic peaks.

\section{$M C 1 R$ gene expression in different skin regions}

Several skin specimens were sampled from two rabbits (one Rhinelander rabbit and one Japanese solid rabbit) just after moulting. Skin samples were collected from regions with different hair colours (white, black and red). Total RNA was isolated, retrotranscribed and amplified to evaluate (as a simple fragment size analysis) the presence of $M C 1 R$ transcripts including the c.125_130del6 mutation (see Methods). In all skin samples with black hair a transcript with expected size was identified whereas no amplification was obtained from skins of both red or white hair regions (Figures $3 \mathrm{~A}$ and 3B). A control glyceraldehyde 3-phosphate dehydrogenase $(G A P D H)$ cDNA fragment was amplified from all skin samples (Additional file 2). Amplification of DNA extracted from the same skin samples used for RNA analysis showed the expected $M C 1 R$ gene fragment (with the c.125_130del6 mutation) (Figure 3).

\section{Discussion}

According to the results we obtained, the c. [124G>A;125_130del6] composite mutation is associated with the $e^{J}$ allele at the rabbit Extension series. This is the third in-frame $M C 1 R$ mutation associated with a coat colour in rabbit, making this species quite unique. One $M C 1 R$ allele determined by a nonframeshift deletion associated only with melanism has been observed in each of other four species (jaguar, jaguarundi, squirrel and guinea fowl) $[23,26,30]$.

The c.280_285del6 rabbit allele $\left(E^{D}\right.$ or $\left.E^{S}\right)$, that eliminates two amino acids in the second transmembrane domain), may determine a constitutive activation of the MC1R protein, that in turn, drives eumelanin production. It seems that the $e^{J}$ in-frame mutation that eliminates two amino acids in the first transmembrane domain (including an amino acid substitution at position 44) could cause the melanic phenotype of the black skin areas by either determining constitutive activation of the receptor or increasing the affinity to $\alpha \mathrm{MSH}$. Otherwise, the presence of black spots or black hairs in Rhinelander and Japanese rabbits could not be explained. The black of the Japanese and tricolour rabbits has been also suggested to be dominant by the pioneering studies of Castle [36] and Punnett [37]. The nonagouti insertion [45] is not the causative mutation of the black areas in these animals for the following reasons: i) in our population survey, all three genotypes for the c.5_6insA ASIP mutation [45] were identified in Japanese and Rhinelander rabbits, but their coat colour did not apparently differ; ii) as the Extension locus should be epistatic over the Agouti locus, the presence of at least a wild type allele is needed to show the allelic status at the Agouti locus, and the $e^{J}$ allele seems clearly a non wild-type allele, at least in our crossbreeding experiments; iii) classical genetic studies indicated that the presence of any Agouti allele does not alter the black in the Japanese rabbits [36,37]. It could be also possible that (an)other not yet identified mutation(s) in the promoter region of the ASIP gene can determine the black phenotype in rabbits not homozygous for the c.5_6insA ASIP mutation but this hypothesis is quite remote as we did not have any evidence of the presence of other non-agouti mutations in a survey that included 31 rabbit breeds [45]. According to classical genetic 
studies [36,37] and to our results, the $e^{J}$ allele is dominant (or partially dominant) over the $e$ allele but recessive over the other alleles of the Extension series. Another example of recessive melanism determined by an in-frame deletion in the $M C 1 R$ gene has been recently reported in guinea fowl [30]. However, to obtain a direct experimental proof of the effects of the $e^{J}$ in-frame composite deletion on the receptor activities and interactions in rabbit pharmacological studies should be carried out.

It also remains to be explained the presence of red coat colour areas associated with this mutation. The effect of the rabbit $e^{J}$ allele resembles the mosaicism of the sex linked Orange locus in female cat and that of Sex linked yellow in female Syrian hamster [38,39]. The Lyon hypothesis for random X inactivation [46] can explain the two sex linked phenotypes in heterozygous animals carrying both a wild-type allele and a mutated allele. However the rabbit Extension is an autosomal locus and the mosaic phenotype is present in homozygous $e^{J} / e^{J}$ animals (or in $e^{J} / e$ rabbits, in which the $e^{J}$ allele is dominant). Komai $[47,48]$ suggested that the Japanese brindling coat colour in rabbit could be determined by both $E^{D}$ and $e$ alleles that are present on the same chromosome as a result of unequal crossing-over. Searle [3] re-interpreted Komai hypothesis [47,48] from the point of view of dosage compensation as Lyon [46] looked at the situation of X-linked loci. Of the two alleles $\left(E^{D}\right.$ and $e$ ) on the same chromosome only one can be active in each chromosome so as to achieve the correct gene dosage. As the $E^{D}$ is dominant, all cell types in which at least a copy of $E^{D}$ would be active (in one or the other chromosome) produce black hair, whereas the cells in which all $E^{D}$ are not active (that phenotypically appear $e / e$ ) would produce yellow/red hair. The result would be a brindled effect with black predominating over red. In case of heterozygous $e^{J} / e$ this hypothesis would predict that half the cells give black hair and half red hair, but as inactivation is random there could be $e^{J} / e$ rabbits that are completely or almost completely red, as reported by Castle [36] and Punnett [37]. According to our results, the Komai-Searle hypothesis cannot be confirmed. The $e^{J}$ allele is different from both the $E^{D}$ and $e$ alleles that are caused by distinct nonframeshift deletions.

Another hypothesis on the presence of autosomal variegation was suggested by Chase [49] who indicated that this phenotype in $e^{p} / \mathrm{e}^{p}$ guinea-pigs could be the result of unstable genes. Somatic mutations to black could occur in yellow mutants. In pigs, a high frequency of somatic reversion of a frameshift mutation in the MC1R gene cause black spotting in a red background [14]. This reversion re-establishes the correct reading frame in a $M C 1 R$ transcript that includes another missense mutation (p.D121N) associated with the dominant black coat colour [13]. However, the evidence obtained for the rabbit Japanese brindling coat colour may indicate that the mechanism determining this phenotype is different from what was observed in pigs. In pigs, the 2 bp mutation determining the $E^{p}$ allele causes a frameshift mutation in the CDS sequence of the pig MC1R gene producing a transcript that includes a premature stop at codon 56 whereas the rabbit $e^{J}$ allele is determined by a nonframeshift deletion that could be predicted to maintain the MC1R action. In pigs, gene expression evaluation in red skin spots showed the presence of the mutated MC1R transcript only (including the $2 \mathrm{bp}$ insertion) whereas two $M C 1 R$ transcripts, one with the insertion of $2 \mathrm{bp}$ and one reversed (without this insertion), were detected in black skin spots [14]. This was not unexpected since partial expression of the non mutated transcript should be sufficient to restore the dominant black coat colour in pigs [14]. In Japanese and Rhinelander rabbits, only one $M C 1 R$ transcript (having the $6 \mathrm{bp}$ deletion of the $e^{J}$ allele) was observed in black hair skin regions whereas red regions did not express any $M C 1 R$ transcript (at least at the level of sensitivity of our qualitative RT-PCR). However, the MC1R gene (including the $6 \mathrm{bp}$ deletion of the $e^{J}$ allele) was amplified from DNA isolated from black and red skin regions indicating that somatic disrupting mutations did not occur in pheomelanic regions. Even if these results were obtained in a few animals, based on these evidences it could be possible to suppose that a regulatory mechanism, driven by another mutation in linkage disequilibrium with the c.[124G>A;125_130del6] composite mutation or by the same composite mutation, may determine the Japanese brindling phenotype in rabbits. To identify a promoter polymorphism we sequenced about $1 \mathrm{~kb}$ of the $M C 1 R$ gene 5'-flanking region in two Japanese and in two Checkered Giant rabbits but we did not find any sequence difference (data not shown). Regulation of $M C 1 R$ expression might be epigenetically determined as already reported for other genes [50,51]. Constitutive methylation of the $M C 1 R$ promoter could inhibits $M C 1 R$ expression causing red coat colour. On the other hand, DNA hypomethylation in some cellular skin clones could lead MC1R expression that might determine black coat colour. In this case, as also similarly hypothesized in pigs, since the expression of one of the two copies is sufficient to restore a dominant black coat colour [14], this mechanism could act by chance in one or the other gene promoter of the diploid somatic skin cells. A dose-effect mechanism that could confirm this hypothesis was evident in the $e^{J} / e$ tricolour rabbits (in which the $e$ allele produces a non functional MC1R receptor [35]) obtained crossing a Rhinelander buck with a Thuringian doe (Additional file 3). In these 
rabbits there is a preponderance of the red spots over the black spots compared to tricolour $e^{J} / e^{J}$ rabbits. A similar observation has been reported by Castle [36] and Punnett [37] who even showed that, as an extreme phenotype, some $e^{J} / e$ rabbits did not have black hair. It is worthwhile to mention that the data in our hands cannot formally exclude the possibility that the Japanese coat colour is caused by a frequent somatic mutation in a regulatory region that re-establishes the $M C 1 R$ gene expression. However, this mechanism cannot completely explain the Japanese brindling in solid coloured rabbits. These animals could have striped-like patterns of black and red as well as brindle-like phenotypes in specific body regions for which a directional epigenetic activation or silencing could be a plausible explanation instead of a random somatic mutation reverting the phenotype in clone-derived cell lines, as in the case of the $E^{p}$ allele in spotted pigs.

\section{Conclusions}

We have identified a novel composite mutation in the rabbit $M C 1 R$ gene associated with the Japanese brindling coat colour phenotype that is a mixture of yellow/ red and black hairs. In the case of the epistatic interaction with another locus (English spotting), it assumes the tricolour pattern with well defined red and black spots. This mutation might be responsible for a dominant (over allele $e$ ) or recessive (over other Extension alleles) eumelanin production in the black hair skin regions. However, the mechanism(s) that cause(s) the presence of both red and black hairs in the same animal seems more complex. Results we obtained about the expression of the $e^{J}$ allele indicate that a regulatory mechanism, driven by another mutation in linkage disequilibrium or by the same identified composite mutation, could determine the brindling phenotype. Epigenetics could be involved in determining this coat colour phenotype. Other studies are needed to evaluate this hypothesis.

\section{Methods}

\section{Animals and samples}

Blood samples were collected from 10 unrelated Japanese, 10 unrelated Rhinelander and one Burgundy Fawn, one Thuringian, one Checkered Giant, one Giant Grey and one Blue Vienna rabbits registered to the breed herdbook (all these animals were used for sequencing as reported below). Hair root samples were also obtained from: 22 Japanese, 1 Rhinelander and 8 Dutch tricolour rabbits. Three $F_{1}$ families were constructed crossing 1) a Rhinelander buck with a Thuringian doe (obtaining $7 \mathrm{~F}_{1}$ rabbits), 2) the same Rhinelander buck with a Japanese doe (obtaining $9 F_{1}$ rabbits) and 3 ) a Checkered Giant buck (with blue spots) with the same Japanese doe (obtaining $10 \mathrm{~F}_{1}$ rabbits). Two $\mathrm{F}_{1}$ rabbits of the latter family were crossed producing one $F_{2}$ family (9 rabbits). Blood samples were collected from all these animals after slaughtering at slaughterhouse and stored at $-20^{\circ} \mathrm{C}$. Pictures were taken from all $F_{1}, F_{2}$ and parental rabbits. Skin samples were collected at the slaughterhouse from one Japanese and two Rhinelander rabbits slaughtered just after moulting. These samples were obtained from completely red, black and, in Rhinelander rabbits, also from completely white hair skin regions. In the Japanese rabbit used for skin sampling it was possible to identify completely red and completely black hair regions. Skin specimens were immediately snap frozen in liquid nitrogen and stored at $-80^{\circ} \mathrm{C}$.

Hair root samples were also collected from additional 315 rabbits belonging to other 29 different breeds (including the Dutch breed, for which animals with other coat colours were sampled) (Table 1). All these rabbits were registered to their breed herdbooks.

\section{Sequencing of the MC1R and ASIP genes}

DNA was extracted from blood and skin samples using the Wizard ${ }^{\circledR}$ Genomic DNA Purification kit (Promega Corporation, Madison, WI) or using rapid extraction methods for hair roots [35,52]. Primers for rabbit MC1R amplification and sequencing (Additional file 4) were already reported [35] or newly designed using PRIMER3 (Whitehead Institute for Biomedical Research, Cambridge, MA) on consensus gene regions obtained aligning the $M C 1 R$ gene in different species or obtained using rabbit trace record sequences belonging to the $M C 1 R$ gene identified by BLASTN analysis. Primers for $A S I P$ sequencing (the three coding exons and part of intronic regions) were previously reported [45]. MC1R gene sequences were obtained from the 10 Japanese and 10 Rhinelander sampled rabbits and from one Burgundy Fawn, one Thuringian, one Giant Grey, one Vienna Blue and one Checkered Giant rabbits already genotyped for the previously detected in-frame deletions [35,52]. ASIP gene sequences were obtained for two Japanese or Rhinelander rabbits for each c.5_6insA ASIP genotype, as previously determined [45]. PCR was performed using a TGradient thermal cycler (Biometra, Goettingen, Germany) or a PT-100 thermal cycler (MJ Research, Watertown, MA, USA) in a volume of $20 \mu \mathrm{L}$ containing 10100 ng DNA template, 1 U DNA EuroTaq DNA polymerase (EuroClone Ltd., Paington, Devon, UK), 1× PCR Buffer, $2.5 \mathrm{mM}$ dNTPs, $10 \mathrm{pmol}$ of each primer and optimised $\mathrm{MgCl}_{2}$ concentrations (from 2.0 to $2.5 \mathrm{mM}$ ). PCR profile was as follows: $5 \mathrm{~min}$ at $95^{\circ} \mathrm{C}$; 35 amplification cycles of $30 \mathrm{~s}$ at $95^{\circ} \mathrm{C}, 30 \mathrm{~s}$ at $60 / 65^{\circ} \mathrm{C}, 30 \mathrm{~s}$ at $72^{\circ} \mathrm{C}$; $5 \mathrm{~min}$ at $72^{\circ} \mathrm{C}$. For sequencing, $3-5 \mu \mathrm{L}$ of PCR product 
was treated with $2 \mu \mathrm{L}$ of ExoSAP-IT ${ }^{\oplus}$ (USB Corporation, Cleveland, Ohio, USA) following the manufacturer's protocol. Cycle sequencing of the PCR products was obtained with the Big Dye v3.1 kit (Applied Biosystems, Foster City, CA, USA) and sequencing reactions, after a few purification steps using EDTA $0.125 \mathrm{M}$, Ethanol $100 \%$ and Ethanol 70\%, were loaded on an ABI3100 Avant sequencer (Applied Biosystems). All sequences were visually inspected, edited, assembled, and aligned with the help of the BioEdit software v. 7.0.5.2 http:// www.mbio.ncsu.edu/BioEdit/bioedit.html and the CodonCode Aligner software http://www.codoncode. com/aligner.

\section{Genotyping}

Analysis of the novel 6 bp deletion was obtained by amplification of a portion of the $M C 1 R$ gene (Additional file 4) and by capillary electrophoresis for fragment analysis. Genotyping of this mutation was carried out using DNA samples extracted from blood or hair root samples collected from the 371 rabbits of different breeds and from the rabbits of the three $F_{1}$ and $F_{2}$ families. Genotypes were also obtained from DNA extracted from skin samples. All these animals were also genotyped for the other two in-frame $M C 1 R$ deletions associated with the $e$ and $E^{D}$ (or $E^{S}$ ) alleles already identified [35,52] and by the ASIP insertion associated with the black nonagouti coat colour we recently reported [45]. To analyse the novel 6 bp deletion, PCR profile was as described above and as reported in Additional file 4. Amplification was obtained in a final volume of $10 \mu \mathrm{L}$ with the forward primer labelled with 6-FAM at 5' (Additional file 4). Amplified products were loaded on a ABI3100 Avant capillary sequencer (Applied Biosystems). For this analysis $1-2 \mu \mathrm{L}$ of reaction product was diluted in $10 \mu \mathrm{L}$ of $\mathrm{Hi}$-Di formamide (Applied Biosystems) and added to 0.1 $\mu \mathrm{L}$ of Rox labelled DNA ladders (500HD Rox, Applied Biosystems). Labelled DNA fragments were sized using GeneScan v. 3.7 and Genotyper v. 3.7 software (Applied Biosystems).

\section{RNA extraction and RT-PCR}

Isolation of total RNA from rabbit skin specimens (about $100 \mathrm{mg}$ ) was carried out using the RNeasy ${ }^{\circledR}$ Lipid Tissue kit (Qiagen) following the manufacturer's instructions. After RNA extraction, about $1 \mu \mathrm{g}$ of total RNA was treated by RNase-Free DNase set (Qiagen) and $40 \mathrm{ng}$ were retrotranscribed with Improm II Reverse Transcription system (Promega) using oligo(dT) primers and following the manufacturer's protocol. cDNA was amplified with the same primers used for genotyping the $6 \mathrm{bp}$ novel $M C 1 R$ deletion as reported above and in Additional file 4. Two-three $\mu \mathrm{L}$ of amplified fragments were loaded in a ABI3100 Avant capillary sequencer (Applied Biosystems) as described above. GAPDH cDNA amplification was used as reference (Additional files 2 and 4). GAPDH fragments were electrophoresed in $10 \%$ polyacryamide:bisacrylamide 29:1 TBE 1× gels and visualized with 1× GelRed Nucleid Acid Gel Stain (Biotium Inc., Hayward, CA, USA). PCR fragments of the $M C 1 R$ gene obtained with non labelled primers were also confirmed by sequencing as described above.

\section{Additional material}

Additional file 1: Three $F_{1}$ rabbit families obtained crossing animals of different breeds with different genotypes at the Extension locus Family 1 is obtained crossing a Rhinelander buck with a Thuringian doe, Family 2 is obtained crossing a Rhinelander buck with a Japanese doe, Family 3 is obtained crossing a Checkered Giant buck with a Japanese doe. The C.280_285del6 ( $E^{D}$ or $\left.E^{S}\right)$, C.304_333del30 (e), and C.

[124A;125_130del6] $\left(e^{J}\right)$ alleles have been indicated as $\Delta 6^{\mathrm{DS}}, \Delta 30, \Delta \sigma^{\jmath}$, respectively. The MCIR genotypes of the parental animals is reported together with the genotype and coat colours of the $F_{1}$ rabbits. All parental animals were homozygous for the nonagouti mutation identified in the ASIP gene [45]. The Checkered Giant buck of family 3 is homozygous for a recessive Dilute locus allele $(d)$ determining the blue coat colour $[3,32,33]$

Additional file 2: GAPDH cDNA fragment amplified from retrotranscribed RNA extracted from skin specimens. Lines $A$ and $B$ : from black hair skin regions of a Rhinelander rabbit. Lines $C$ and $D$ : from red hair skin regions of a Rhinelander rabbit. Line E: control genomic DNA. Line F: DNA ladder.

Additional file 3: Tricolour rabbits with $\Delta 6^{\mathrm{J}} / \Delta 30$ (A) and $\Delta 6^{\mathrm{J}} / \Delta 6^{\mathrm{J}}$ (B) genotypes. Rabbits with these two genotypes differ in terms of extension of black regions.

Additional file 4: Primers and PCR conditions. Primer sequences, PCR conditions and use of the reported primer pairs.

\section{Acknowledgements}

We thank people who helped in the sampling: a particular thank is for Renate Regitz (Germany) who provided many Japanese and the Dutch tricolour samples. Associazione Nazionale Coniglicoltori Italiani (ANCI) (Italy) collaborated during the collection of samples. This work was financed by University of Bologna RFO and FAGenomicH funds to LuF and was supported by University of Limoges and INRA.

\section{Author details}

'DIPROVAL, Sezione di Allevamenti Zootecnici, University of Bologna, Via F.lli Rosselli 107, 42123 Reggio Emilia, Italy. ${ }^{2}$ INRA, UMR1061 Unité de Génétique Moléculaire Animale, Université de Limoges, 87060 Limoges Cedex, France. 3 UR967, Génétique Expérimentale en Productions Animales, INRA, 17700 Surgères, France. ${ }^{4}$ UR631, Station d'Amélioration Génétique des Animaux, INRA, 31326 Castanet Tolosan, France.

\section{Authors' contributions}

LuF conceived the study, analysed sequences and obtained data, contributed to the sampling and to the construction of rabbit families, coordinated and organized the laboratory work and drafted the manuscript. ES reared the rabbit families, genotyped and collaborated in the RT-PCR analyses. MC performed the RT-PCR experiment. FB and LiF sequenced and genotyped. SD, DA and SDe collected samples. DA, VR supervised the work and were involved in the design of the study. AO co-conceived the study, contributed to the sampling and to drafting the manuscript. All authors reviewed the manuscript and accepted the final version.

Received: 5 February 2010 Accepted: 1 July 2010 Published: 1 July 2010 


\section{References}

1. Bennett DC, Lamoreux ML: The color loci of mice - a genetic century. Pigment Cell Res 2003, 16:333-344.

2. Montoliu L, Oetting WS, Bennett DC: Color Genes. European Society for Pigment Cell Research 2009 [http://www.espcr.org/micemut]

3. Searle AG: Comparative Genetics of Coat Colour in Mammals London: Logos Press 1968.

4. Robbins LS, Nadeau JH, Johnson KR, Kelly MA, Roselli-Rehfuss L, Baack E, Mountjoy KG, Cone RD: Pigmentation phenotypes of variant extension locus alleles result from point mutations that alter MSH receptor function. Cell 1993, 72:827-834.

5. Bultman SJ, Michaud EJ, Woychik RP: Molecular characterization of the mouse agouti locus. Cell 1992, 71:1195-1204.

6. Lu D, Willard D, Patel IR, Kadwell S, Overton L, Kost T, Luther M, Chen W, Woychik RP, Wilkison WO, Cone RD: Agouti protein is an antagonist of the melanocyte-stimulating-hormone receptor. Nature 1994, 371:799-802

7. Ollmann MM, Lamoreux ML, Wilson BD, Barsh GS: Interaction of Agouti protein with the melanocortin 1 receptor in vitro and in vivo. Genes Dev 1998, 12:316-330.

8. Valverde P, Healy E, Jackson I, Rees JL, Thody AJ: Variants of the melanocyte-stimulating hormone receptor gene are associated with red hair and fair skin in humans. Nat Genet 1995, 11:328-330.

9. Cone RD, Lu D, Koppula S, Våge DI, Klungland H, Boston B, Chen W, Orth DN, Pouton C, Kesterson RA: The melanocortin receptors: agonists, antagonists, and the hormonal control of pigmentation. Recent Prog Horm Res 1996, 51:287-317

10. Klungland H, Våge DI, Gomez-Raya L, Adalsteinsson S, Lien S: The role of melanocyte-stimulating hormone $(\mathrm{MSH})$ receptor in bovine coat color determination. Mamm Genome 1995, 6:636-639.

11. Joerg H, Fries HR, Meijerink E, Stranzinger GF: Red coat color in Holstein cattle is associated with a deletion in the MSHR gene. Mamm Genome 1996, 7:317-318

12. Rouzaud F, Martin J, Gallet PF, Delourme D, Goulemot-Leger V, Amigues $Y$, Ménissier $F$, Levéziel $H$, Julien $R$, Oulmouden A: A first genotyping assay of French cattle breeds based on a new allele of the extension gene encoding the melanocortin-1 receptor (Mc1r). Genet Sel Evol 2000, 32:511-520.

13. Kijas JMH, Wales $R$, Törnsten A, Chardon P, Moller M, Andersson L: Melanocortin receptor 1 (MC1R) mutations and coat color in pigs. Genetics 1998, 150:1177-1185.

14. Kijas JM, Moller M, Plastow $G$, Andersson L: A frameshift mutation in MC1R and a high frequency of somatic reversions cause black spotting in pigs. Genetics 2001, 158:779-785.

15. Marklund $L$, Johansson Moller M, Sandberg $K$, Andersson $L$ : A missense mutation in the gene for melanocyte-stimulating hormone receptor (MC1R) is associated with the chestnut coat color in horses. Mamm Genome 1996, 7:895-899.

16. Våge DI, Klungland $H$, Lu D, Cone RD: Molecular and pharmacological characterization of dominant black coat color in sheep. Mamm Genome 1999, 10:39-43

17. Fontanesi L, Beretti F, Riggio V, Dall'Olio S, Gómez González E, Finocchiaro R, Davoli R, Russo V, Portolano B: Missense and nonsense mutations in melanocortin 1 receptor $(M C 1 R)$ gene of different goat breeds: association with red and black coat colour phenotypes but with unexpected evidences. BMC Genet 2009, 10:47.

18. Newton JM, Wilkie AL, He L, Jordan SA, Metallinos DL, Holmes NG, Jackson IJ, Barsh GS: Melanocortin 1 receptor variation in the domestic dog. Mamm Genome 2000, 11:24-30.

19. Everts RE, Rothuizen J, van Oost BA: Identification of a premature stop codon in the melanocyte-stimulating hormone receptor gene $(M C 1 R)$ in Labrador and Golden retrievers with yellow coat colour. Anim Genet 2000, 31:194-199.

20. Våge $\mathrm{Dl}$, Lu D, Klungland $\mathrm{H}$, Lien S, Adalsteinsson S, Cone RD: A nonepistatic interaction of agouti and extension in the fox, Vulpes vulpes. Nat Genet 1997, 15:311-315.

21. Våge DI, Fuglei E, Snipstad K, Beheim J, Landsem VM, Klungland H: Two cysteine substitutions in the $M C 1 R$ generate the blue variant of the Arctic fox (Alopex lagopus) and prevent expression of the white winter coat. Peptides 2005, 26:1814-1817.

22. Ritland $\mathrm{K}$, Newton $\mathrm{C}$, Marshall HD: Inheritance and population structure of the white-phased "Kermode" black bear. Curr Biol 2001, 11:1468-1472.
23. Eizirik E, Yuhki N, Johnson WE, Menotti-Raymond M, Hannah SS, O'Brien SJ: Molecular genetics and evolution of melanism in the cat family. Curr Biol 2003, 13:448-453.

24. Nachman MW, Hoekstra HE, D'Agostino SL: The genetic basis of adaptive melanism in pocket mice. Proc Natl Acad Sci USA 2003, 100:5268-5273.

25. Hoekstra HE, Hirschmann RJ, Bundey RA, Insel PA, Crossland JP: A single amino acid mutation contributes to adaptive beach mouse color pattern. Science 2006, 313:101-104.

26. McRobie $\mathrm{H}$, Thomas A, Kelly J: The genetic basis of melanism in the gray squirrel (Sciurus carolinensis). J Hered 2009, 100:709-714.

27. Kerje $\mathrm{S}$, Lind J, Schütz $\mathrm{K}$, Jensen $\mathrm{P}$, Andersson L: Melanocortin 1-receptor $(M C 1 R)$ mutations are associated with plumage colour in chicken. Anim Genet 2003, 34:241-248.

28. Nadeau NJ, Minvielle F, Mundy NI: Association of a Glu92Lys substitution in MC1R with extended brown in Japanese quail (Coturnix japonica). Anim Genet 2006, 37:287-289.

29. Theron E, Hawkins K, Bermingham E, Ricklefs RE, Mundy NI: The molecular basis of an avian plumage polymorphism in the wild: a melanocortin-1receptor point mutation is perfectly associated with the melanic plumage morph of the bananaquit, Coereba flaveola. Curr Biol 2001, 11:550-557.

30. Vidal O, Araguas RM, Fernández R, Heras S, Pla C: Melanism in guinea fowl (Numida meleagris) is associated with a deletion of Phenilalanine-256 in the MC1R gene. Anim Genet, doi:10.1111/j.1365-2052.2010.02056.x.

31. Rosenblum EB, Hoekstra HE, Nachman MW: Adaptive reptile color variation and the evolution of the Mc1r gene. Evolution 2004 58:1794-1808.

32. Castle WE: The Genetics of Domestic Rabbit London, Cambridge Harvard University Press 1930

33. Robinson R: Genetic studies of the rabbit. Bibliogr Genet 1958, 17:229-558.

34. Fox RR: Taxonomy and Genetics. The Biology of the Laboratory Rabbit Academic Press, San Diego, CAManning PJ, Ringler DH, Newcomer CE, Second 1994, 1-26.

35. Fontanesi L, Tazzoli M, Beretti F, Russo V: Mutations in the melanocortin 1 receptor $(M C 1 R)$ gene are associated with coat colours in the domestic rabbit (Oryctolagus cuniculus). Anim Genet 2006, 37:489-493.

36. Castle WE: Genetics of the Japanese rabbit. J Genet 1924, 14:225-229.

37. Punnett RC: On the "Japanese" rabbit. J Genet 1924, 14:230-240.

38. Schmidt-Küntzel A, Nelson G, David VA, Schäffer AA, Eizirik E, Roelke ME, Kehler JS, Hannah SS, O'Brien SJ, Menotti-Raymond M: A domestic cat X chromosome linkage map and the sex-linked orange locus: mapping of orange, multiple origins and epistasis over nonagouti. Genetics 2009, 181:1415-1425

39. Alizadeh A, Hong LZ, Kaelin CB, Raudsepp T, Manuel H, Barsh GS: Genetics of Sex-linked yellow in the Syrian hamster. Genetics 2009, 181:1427-1436.

40. Wright $S$ : Colour inheritance in mammals - V. The guinea pig. J Hered 1917, 8:476-480.

41. Wright S: The relation between piebald and tortoiseshell color patterns in guinea pigs. Anat Rec 1923, 26:393.

42. Fontanesi L, Vargiolu M, Scotti E, Mazzoni M, Clavenzani P, De Giorgio R, Romeo G, Russo V: Endothelin receptor $\mathrm{B}(E D N R B)$ is not the causative gene of the English spotting locus in the domestic rabbit (Oryctolagus cuniculus). Anim Genet, doi:10.1111/j.1365-2052.2010.02084.x.

43. Marklund S, Kijas J, Rodriguez-Martinez H, Rönnstrand L, Funa K, Moller M, Lange D, Edfors-Lilja I, Andersson L: Molecular basis for the dominant white phenotype in the domestic pig. Genome Res 1998, 8:826-833.

44. Aigner B, Besenfelder U, Müller M, Brem G: Tyrosinase gene variants in different rabbit strains. Mamm Genome 2000, 11:700-702

45. Fontanesi L, Forestier L, Allain D, Scotti E, Beretti F, Deretz-Picoulet S, Pecchioli E, Vernesi C, Robinson TJ, Malaney JL, Russo V, Oulmouden A: Characterization of the rabbit agouti signaling protein (ASIP) gene: Transcripts and phylogenetic analyses and identification of the causative mutation of the nonagouti black coat colour. Genomics 2010, 95:166-175.

46. Lyon MF: Gene action in the X-chromosome of the mouse (Mus musculus L.). Nature 1961, 190:372-373.

47. Komai T: Semi-allelic genes. Amer Nat 1950, 84:381-392.

48. Komai T: On mosaic inheritance in mammals. Amer Nat 1951, 85:333-334.

49. Chase HB: Studies on the tricolor pattern of the guinea-pig - II. The distribution of black and yellow as affected by white spotting and by imperfect dominance in the tortoiseshell series of alleles. Genetics 1939 24:610-643. 
50. Kass SU, Pruss D, Wolffe AP: How does DNA methylation repress transcription? Trends Genet 1997, 13:444-449.

51. Shen L, Kondo Y, Guo Y, Zhang J, Zhang L, Ahmed S, Shu J, Chen X, Waterland RA, Issa JP: Genome-wide profiling of DNA methylation reveals a class of normally methylated CpG island promoters. PLoS Genet 2007, 3:2023-2036.

52. Fontanesi L, Tazzoli M, Russo V: Non-invasive and simple methods for sampling DNA for PCR analysis of melanocortin 1 receptor (MC1R) gene mutations: a technical note. World Rabbit Sci 2007, 15:121-126.

doi:10.1186/1471-2156-11-59

Cite this article as: Fontanesi et al.: A composite six bp in-frame deletion in the melanocortin 1 receptor (MC1R) gene is associated with the Japanese brindling coat colour in rabbits (Oryctolagus cuniculus). BMC Genetics 2010 11:59.

Submit your next manuscript to BioMed Central and take full advantage of:

- Convenient online submission

- Thorough peer review

- No space constraints or color figure charges

- Immediate publication on acceptance

- Inclusion in PubMed, CAS, Scopus and Google Scholar

- Research which is freely available for redistribution

Submit your manuscript at www.biomedcentral.com/submit 